\title{
Breast feeding in infancy and recurrent cough in adulthood: the longer the better?
}

\section{Erick Forno}

Breast feeding has been associated with many beneficial outcomes in children. Among other benefits, it has been linked to lower infant mortality, ${ }^{1}$ lower risk of sudden infant death syndrome, ${ }^{2}$ lower incidence of certain types of cancer $^{3}$ and even higher intelligence. ${ }^{4}$ In terms of atopy and respiratory diseases, it has been associated with decreased risk of lower respiratory infections (LRIs) ${ }^{5}$ and childhood asthma (particularly over the first few years of life). ${ }^{67}$ On the other hand, a recent meta-analysis found no strong evidence that breast feeding helps prevent food allergies, eczema or allergic rhinitis. ${ }^{8}$ However, many studies looking at respiratory outcomes recorded breast feeding retrospectively or failed to thoroughly control for potentially important confounders. ${ }^{9}$

Whether these benefits extend into adulthood is still an open question. For example, a history of breast feeding may not affect the risk of high total cholesterol, high blood pressure or cardiovascular mortality. ${ }^{10}$ Unfortunately, studies evaluating the association between breast feeding and asthma in adults are scarce and have provided somewhat concerning results. In the Dunedin cohort, Sears et al reported an $\sim 83 \%$ increased risk of asthma at 9-26 years of age among participants who were breast fed in infancy compared with those who were not breast fed. ${ }^{11}$ Likewise, the Tasmanian Asthma Study reported that exclusively breastfed children (of mothers with a history of atopy) had 46\%-83\% higher risk of asthma at 14, 32 and 44 years of age, with similar results for allergic rhinitis. ${ }^{12}$ However, these cohorts were recruited at 3 and 7 years of age, respectively, and thus breastfeeding information may have been subject to recall bias.

In their study, Gerhart et $a l^{13}$ go a step further to answer the question of whether breast feeding is associated with respiratory symptoms later in life. Using data from the Tucson Children's Respiratory Study (TCRS) - perhaps the most

Correspondence to Dr Erick Forno, Division of Pediatric Pulmonary Medicine, University of Pittsburgh, Pittsburgh, PA 15224, USA; erick.forno@chp.edu influential epidemiological birth cohort of childhood asthma-the authors evaluate the association between breastfeeding duration and the presence of recurrent cough in 735 cohort participants at 22, 26 and 32 years of age. They report that breast feeding for $\geq 4$ months is associated with $\sim 28 \%$ lower risk of recurrent cough during early adulthood (adjusted OR $0.72,95 \%$ CI 0.56 to 0.90 ) after adjusting for sex, race/ethnicity and participant smoking, as well as parental age, education, smoking and asthma. The results are very interesting and point to very longterm effects of breast feeding on respiratory symptoms. Chief among the strengths of the study are the use of detailed data collected prospectively during infancy, the non-selected nature of the original cohort and the relatively high participation rate $(\sim 59 \%$ of the original sample) even three decades later. The study limitations are clearly disclosed by the authors and include the differences between mothers who breast fed and those who did not, the use of self-report to collect adult symptoms (including the outcome) and the fact that subjects who were breast fed for longer as infants were more likely to still be in the cohort at age 32 years.

Exactly how might longer breast feeding protect from recurrent cough 30 years later is not clear. Perhaps the simplest explanation would be that breast feeding is associated with lower risk of asthma, and thus with lower odds of cough; however, the authors report no association between breastfeeding duration and adult asthma, and that additional adjustment for asthma did not alter their results. As the authors suggest, another plausible explanation may include protection from early-life viral LRIs among infants who have been breast fed for a longer period of time which may in turn protect from respiratory symptoms later in life. In this study, early LRI-related wheezing and respiratory syncytial virus (RSV) infections were not associated with recurrent cough in adulthood, although there were some non-significant 'trends' (RSV LRI vs cough at 22 years, $\mathrm{p}=0.07$; and childhood wheezing phenotype vs cough at 22-32 years, $\mathrm{p}=0.06$ ). Thus, we may not be able to completely rule out the potential mediating role of protection from viral LRIs or early wheeze. Another possibility would be that immune globulins or other factors in breast milk may modulate the microbiome $^{1415}$ or induce epigenetic changes ${ }^{16}$ during a time period that is crucial for the infant's immune system development and maturation. Infant feeding patterns have been associated with other diseases, such as Crohn's disease, ulcerative colitis ${ }^{17}$ or diabetes, ${ }^{18}$ in which immunity and inflammation also play prominent roles.

Of interest, in the study by Gerhart et al participants with earlier introduction of formula were more likely to report tobacco smoking at 22 years (but not at 26 or 32 years), and participant smoking was associated with recurrent cough (and with wheezing) at all three time points. Moreover, maternal and paternal smoking were associated with shorter breastfeeding duration. While the statistical models were adjusted for participant and parental smoking, these associations may reflect unmeasured or unknown factors that may partly affect the risk of recurrent cough. The same may be true for data completeness: participants who were breast fed longer were more likely to still be in the study at age 32 . While this only happened at the last time point, that visit was precisely the one with the most statistically robust association, and this may suggest that there are some unmeasured characteristics of study participants that associate with breast feeding and that could partially explain the risk of recurrent cough. Other potential confounders include rhinitis, chronic sinusitis and heartburn, all of which were more frequently reported by subjects with recurrent cough. However, adjusting for these characteristics did not alter the results, making it less likely that these diseases were responsible for the observed associations.

Finally, another interesting possibility would be that lung function (or lung function deficits) might mediate the reported results. Given the association between breastfeeding duration and forced vital capacity (FVC) at 16 years of age in the TCRS cohort, ${ }^{19}$ the authors adjusted the models in the current study for FVC and found no significant changes in their results. However, they did not evaluate forced expiratory volume in 1s $\left(\mathrm{FEV}_{1}\right)$ or $\mathrm{FEV}_{1} / \mathrm{FVC}$. This is particularly important because breast feeding has been associated with higher $\mathrm{FEF}_{50}$ in adolescents ${ }^{20}$ and with higher $\mathrm{FEV}_{1} /$ FVC in young adults ${ }^{21}$ and, as the authors note, recurrent cough in older 
adults has been associated with airway obstruction. $^{22}$ One could hypothesise that breast feeding may lead to improved lung function early on (or to reduced risk of airway obstruction) which is in turn reflected in a reduced risk of chronic cough later in life.

A thought-provoking question that arises but remains unanswered is whether results like these provide a glimpse of a link between protective (or risk) factors for childhood asthma and those for adult lung diseases such as chronic obstructive pulmonary disease (COPD). The 'Dutch hypothesis' was first proposed in 1961 to suggest that asthma and COPD had common origins, and their clinical expressions were part of a 'spectrum'. ${ }^{23}$ Could it be that breast feeding is somehow a piece of the puzzle? More importantly, one of the main ideas formulated with the Dutch hypothesis was to not simply apply a disease label but to carefully characterise patients (what we now call 'phenotyping'), taking into account the interplay between host and environmental factors. ${ }^{23}$ We are all certainly hopeful that the TCRS and other long-term birth or early-life cohorts will continue to follow their altruistic participants for many years to come, and will continue to shed light on the evolution of respiratory health and disease throughout the lifespan.

Funding This study was funded by National Heart, Lung, and Blood Institute (10.13039/100000050), grant number HL125666.

Competing interests None declared.

Patient consent Not required.

Provenance and peer review Commissioned; internally peer reviewed.

(C) Article author(s) (or their employer(s) unless otherwise stated in the text of the article) 2018. All rights reserved. No commercial use is permitted unless otherwise expressly granted.
Check for updates

To cite Forno E. Thorax 2018;73:801-802.

Accepted 7 May 2018

Published Online First 26 May 2018

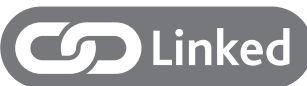

http://dx.doi.org/10.1136/thoraxjnl-2017-210841

Thorax 2018;73:801-802.

doi:10.1136/thoraxjnl-2018-211871

\section{REFERENCES}

1 Sankar MJ, Sinha B, Chowdhury R, et al. Optimal breastfeeding practices and infant and child mortality: a systematic review and meta-analysis. Acta Paediatr 2015; 104:3-13.

2 Thompson JMD, Tanabe K, Moon RY, et al. Duration of breastfeeding and risk of SIDS: an individual participant data meta-analysis. Pediatrics 2017; 140:e20171324.

3 Ma X, Zhao LG, Sun JW, et al. Association between breastfeeding and risk of endometrial cancer: a metaanalysis of epidemiological studies. Eur J Cancer Prev 2018;27:144-51.

4 Horta BL, Loret de Mola C, Victora CG. Breastfeeding and intelligence: a systematic review and metaanalysis. Acta Paediatr 2015;104:14-19.

5 Tromp I, Kiefte-de Jong J, Raat H, et al. Breastfeeding and the risk of respiratory tract infections after infancy: the Generation R Study. PLoS One 2017; 12:e0172763.

6 Dogaru CM, Nyffenegger D, Pescatore AM, et al. Breastfeeding and childhood asthma: systematic review and meta-analysis. Am J Epidemiol 2014;179:1153-67.

7 Scholtens S, Wijga AH, Brunekreef B, et al. Breast feeding, parental allergy and asthma in children followed for 8 years. The PIAMA birth cohort study. Thorax 2009;64:604-9.

8 Lodge CJ, Dharmage SC. Breastfeeding and perinatal exposure, and the risk of asthma and allergies. Curr Opin Allergy Clin Immunol 2016;16:231-6.

9 Victora CG, Bahl R, Barros AJ, et al. Breastfeeding in the 21st century: epidemiology, mechanisms, and lifelong effect. Lancet 2016:387:475-90.

10 Martin RM, Davey Smith G, Mangtani P, et al. Breastfeeding and cardiovascular mortality: the Boyd Orr cohort and a systematic review with meta-analysis. Eur Heart J 2004;25:778-86.
11 Sears MR, Greene JM, Willan AR, et al. Long-term relation between breastfeeding and development of atopy and asthma in children and young adults: a longitudinal study. Lancet 2002;360:901-7.

12 Matheson MC, Erbas B, Balasuriya A, et al. Breastfeeding and atopic disease: a cohort study from childhood to middle age. J Allergy Clin Immunol 2007;120:1051-7.

13 Gerhart KD, Stern DA, Guerra S, et al. Protective effect of breastfeeding on recurrent cough in adulthood. Thorax 2018:thoraxjnl-2017-210841.

14 Biesbroek G, Tsivtsivadze E, Sanders EA, et al. Early respiratory microbiota composition determines bacterial succession patterns and respiratory health in children. Am J Respir Crit Care Med 2014;190:1283-92.

15 Biesbroek G, Bosch AA, Wang $X$, et al. The impact of breastfeeding on nasopharyngeal microbial communities in infants. Am J Respir Crit Care Med 2014;190:298-308.

16 Hartwig FP, Loret de Mola C, Davies NM, et al. Breastfeeding effects on DNA methylation in the offspring: A systematic literature review. PLoS One 2017;12:e0173070.

17 Xu L, Lochhead P, Ko Y, et al. Systematic review with meta-analysis: breastfeeding and the risk of Crohn's disease and ulcerative colitis. Aliment Pharmacol Ther 2017:46:780-9.

18 González-Jiménez E, Montero-Alonso MA, SchmidtRioValle J, et al. Metabolic syndrome in Spanish adolescents and its association with birth weight, breastfeeding duration, maternal smoking, and maternal obesity: a cross-sectional study. Eur J Nutr 2015;54:589-97.

19 Guilbert TW, Stern DA, Morgan WJ, et al. Effect of breastfeeding on lung function in childhood and modulation by maternal asthma and atopy. Am J Respir Crit Care Med 2007;176:843-8.

20 Dogaru CM, Strippoli MP, Spycher BD, et al. Breastfeeding and lung function at school age: does maternal asthma modify the effect? Am J Respir Crit Care Med 2012;185:874-80.

21 Owens L, Laing IA, Zhang G, et al. Can risk factors for COPD be traced back to infancy? The Perth infant asthma follow up study. Eur Respir J 2016;48:0A3305.

22 Wheaton AG, Ford ES, Thompson WW, et al. Pulmonary function, chronic respiratory symptoms, and health-related quality of life among adults in the United States-National Health and Nutrition Examination Survey 2007-2010. BMC Public Health 2013;13:854.

23 Tomas CC, Orie NGM, Sluiter HJ. Bronchitis: an international symposium 27-29 April 1960. Groningen, Netherlands, 1961. 